\title{
Financial behaviour and financial wellbeing of MSMEs actors: The role of financial literacy and cognitive factors
}

\author{
Abdur Rafik*, Aghnia Setyaning Rahayu \\ Faculty of Business and Economics, Universitas Islam Indonesia, Yogyakarta, Indonesia \\ Corresponding authors: abdurrafik@uii.ac.id
}

\begin{abstract}
That financial literacy and psychological characteristics are important determinants of financial decisions have long been recognized in the literature. By focusing on Micro Small Medium Enterprises (MSMEs), this study investigates the extent to which financial behaviour and financial well-being consisting of both financial security and financial anxiety can be explained by financial literacy and cognitive factors such as self-control, optimism, and deliberative thinking. Several demographic factors such as gender, age, educational background, and the length of engaging in MSMEs, as well as the characteristics of MSMEs such as industry and monthly sales turnover are functioned as control variables. Data were collected using a questionnaire that was purposively distributed to MSMEs' actors and analysed using Partial Least Square-Structural Equation Modeling (PLS-SEM). In total, 155 samples were analyzed. The analysis shows that financial behaviour can be explained by deliberative thinking, financial security can be explained by financial literacy and optimism, while financial anxiety can be explained by self-control. Financial behaviour was also found to have a positive direct effect on financial security and financial anxiety. Thus, to improve the financial well-being of MSMEs' actors, it may be necessary to improve their personal financial management skills that can lead to the positivity of financial behaviour.
\end{abstract}

Keywords: financial literacy, financial wellbeing, MSME

JEL Classification Code: G51, G53, D91

DOI: 10.20885/jsb.vol24.iss1.art6

\section{Introduction}

It is widely acknowledged that MSMEs have an important role in economic development (Bloch \& Bhattacharya, 2016; Tambunan, 2005). MSMEs are even considered to be more resilient to crises than large-scale companies are also intensely discussed in the literature although the findings varied (Sato, 2000; Tambunan, 2005; Tambunan, 2019). Because of this crucial role, the role of MSMEs cannot be underestimated and its advocacy and the development are a necessity that must be continuously leveraged.

In the economic literature, the performance and development of any company are often inseparable from the roles and the characteristics of the owners and/or agents. The characteristics, knowledge, habits and personal skills of the owners and/or agents are often a reflection of how the company will be managed and performed. Some researchers such as Nimalathasan (2008), Cronqvist et al. (2012), Maliranta and Nurmi (2019), and Murphy et al. (2019) have succeeded in proving this relationship through various studies with diverse settings. Those who have high discipline in managing personal finances, for example, have the potential to also be more disciplined in managing corporate finance if they get an opportunity or authority to run a company. This assumption is in line with behavioural consistency theory in psychology which states that the one's behaviour will tend to be consistent in various conditions (Sherman et al., 2010).

Therefore, studying how financial behaviours and perceived financial well-being of MSMEs' actors, which are mostly the owners, can be one of the entrances to learn how MSMEs might develop in the future. In the literature, it is widely identified that financial behaviours and financial well-being are influenced by many factors, including financial literacy and individual cognitive capabilities 
(Agarwal \& Mazumder, 2013; Chu et al., 2017; Gerrans et al., 2014; Kamakia et al., 2017; Skagerlund et al., 2018; Taft et al., 2013; Topa et al., 2018).

Financial literacy is deemed as an important factor because it is directly related to the individual knowledge on various aspects of finance and its management. While cognitive factors are considered important because they are directly related to how financial decision making is made. Some researchers such as Chu et al. (2017), Durodola et al. (2017), Gerrans et al. (2014), Kamakia et al. (2017), and Taft et al. (2013) have confirmed a positive relationship between financial literacy and both financial behaviour and financial well-being. Likewise, for several cognitive factors such as selfcontrol (Strömbäck et al., 2017b, 2020), optimism (Hyytinen \& Putkuri, 2018; Strömbäck et al., 2017), and deliberative thinking (Strömbäck et al., 2017, 2020).

This study aims to investigate the extent to which the financial behaviour and financial wellbeing of MSMEs' actors can be explained by their financial literacy and cognitive factors represented by self-control, optimism, and deliberative thinking. This study is different and contributes to theoretical enrichment especially concerning the importance of understanding the financial behaviour and financial well-being models of MSMEs' actors by including not only financial literacy, but also various cognitive factors such as self-control, optimism, and deliberative thinking. In Indonesia, studies trying to model the financial behaviour of MSMEs' actors by including cognitive factors are not much addressed.

\section{Literature Review and Hypotheses}

The existence of MSMEs in Indonesia is regulated in Law No. 20 of 2008. In the Act, it is explained that MSME is a business that is divided into three criteria, namely micro, small and medium whose definition is separated based on the size of assets and sales turnover. Microbusiness is defined as a business that has a maximum asset of 50 million with annual sales turnover does not exceed 300 million, while small business is defined as a business whose assets are $50-500$ million with annual sales turnover between 500 million - 2.5 billion rupiah. While medium business is defined as a business whose assets are between 500 million - 1 billion with an annual sales turnover of 2.5 - 50 billion rupiahs ${ }^{1}$.

Many factors that have been identified affecting MSMEs' performance, ranging from economic and political structures at country level (Ndiaye et al., 2018), firm and management attributes (Quartey \& Oguntoye, 2020; Woldesilassie \& Ivatury, 2020), and characteristics of the owners and/or managers (Asiedu \& Freeman, 2007; Blackburn et al., 2013; Buyinza et al., 2017). The confirmation of a positive relationship between the characteristics of the owner and/or manager with the performance of MSMEs implies that the knowledge, attitudes, and personal values of the owner and/or manager of MSME will be reflected in the management of the firm. This also means, in line with the behavioural consistency theory (Sherman et al., 2010), the financial behaviour exhibited by MSMEs' actors in the personal domain will also be carried into the company when it is authorized to manage. Thus, an analysis of the determinants of the financial behaviour and financial well-being of MSMEs' actors is inevitable so that the development of MSMEs can be effectively carried out through individual interventions.

Financial behaviour is defined as any human behaviour related to financial and money management (Xiao, 2008). This behaviour generally includes saving behaviour, investment behaviour, credit behaviour, and cash behaviour. While financial well-being can be defined as a condition by which one's financial independence has been well achieved. A person can be said to be financially wellness if one based on his subjective evaluation has been able to sustain current and anticipated living standards and financial freedom (Brüggen et al., 2017). According to Strömbäck et al. (2017), two dimensions are equally important in financial well-being, namely financial security and financial anxiety. Financial security can be defined as a condition to which a person feels secure about her/his

\footnotetext{
${ }^{1}$ See details in Law No. 20 of 2008 about Micro Small Medium Enterprises in Indonesia
} 
current financial obligations and future financial conditions. While financial anxiety represents the extent to which a person feels anxious about financial uncertainties and financial-related decision making. In short, financial well-being is the people's perceived representation, both subjectively and objectively, to their financial wellness (Brüggen et al., 2017; Strömbäck et al., 2017b, 2020).

\section{Financial Literacy, Financial Behavior and Financial Wellbeing}

According to Hastings et al., (2013), financial literacy refers to the knowledge of financial concepts and products, as well as the numeracy and skills needed in effective financial decision making. Remund (2010) defines financial literacy as an ability to understand the financial problems as well as the knowledge and the awareness of financial instruments and their application in business and personal life. Because an understanding is an important antecedent of behaviour, those with high financial literacy are expected to be able to make prudent financial decisions so that the outcome will also be good. Therefore, people that are highly financially literated should be able to manage their personal finance in their daily life and understand the impact of their financial decisions on their self, other people, and the environment (Remund, 2010).

Researchers such as Chu et al. (2017), Gathergood (2012), and Gerrans et al. (2014), Strömbäck et al. (2017b), and Taft et al. (2013) has proven a positive relationship between financial literacy and financial behaviour and financial well-being. That is, the higher the financial literacy, the better the financial behaviour, the lesser perceived financial anxiety, and the better the perceived financial security. This is because individuals with high levels of financial literacy will tend to be more careful in allocating and utilizing their money for financial needs. As a result, their financial behaviour will improve and their subjective perception of financial security (anxiety) will also increase (decrease). For this reason, we formulated hypotheses concerning financial literacy as follows.

H1a: The higher the financial literacy, the better the financial behaviour

$\mathrm{H} 1 \mathrm{~b}$ : The higher the financial literacy, the higher the perceived financial security

H1c: The higher the financial literacy, the lower the perceived financial anxiety

\section{Self Control, Financial Behaviour and Financial Wellbeing}

Self-control can be defined as an individual ability to resist temptations that will hinder the achievement of long-term goals. Self-control is influenced by an individuals' will or determination. Someone with high self-control usually has a strong determination to achieve desirable goals (Myrseth \& Fishbach, 2009).

Shefrin and Thaler (1988) propose hypotheses regarding the link of self-control and financial behaviour called the Behavior Life Cycle (BLC). According to BLC hypothesis, individual behaviour represents the conflict between two elements, namely "planner" which tends to be oriented towards the future and "doer" which tends to be oriented toward the present. Furthermore, this hypothesis assumes that everyone tends to treat the composition of wealth as non-fungible and divides it into three main components, namely current income, current assets, and future income. In this regard, because of our mental accounting, the temptation to spend money from current income will always be greater than the temptation to spend money set aside for retirement. Therefore, saving money from current income will seem less easy and costly than money that is set aside for retirement. The implication, according to Shefrin and Thaler (1988), individual financial behaviour will be determined by the ability to control the temptations and costs associated with exercising such controls. Some researchers such as Graham and Isaac (2002), Levin (1998), and Schooley and Worden (2008) have proven the premise of this hypothesis.

According to Strömbäck et al. (2017b), those with high self-control will be able to manage their personal finance wisely compared those with low self-control. This is because individuals with good self-control will be better able to suppress emotions and be more logical in making financial decisions. Furthermore, Ameriks et al. (2007) argue that self-control can be an indicator of the success of one's 
life. This is because self-control affects the mindset and behaviour of each individual. Highly selfcontrolled individuals will be able to make the right decisions and achieve the desired goals in the future. That self-control is one of the important determinants of financial behaviour and financial well-being has been proven by scholars such as Gathergood (2012), Liu et al. (2019), Rha et al. (2006), and Strömbäck et al. (2017b, 2020). Therefore, self-control related hypotheses are formulated as follows.

H2a: The better self-control, the better financial behaviour

$\mathrm{H} 2 \mathrm{~b}$ : The better self-control, the higher the perceived financial security

$\mathrm{H} 2 \mathrm{c}$ : The better self-control, the lower the perceived financial anxiety

\section{Optimism, Financial Behaviour and Financial Wellbeing}

Optimism is a mental attitude that reflects a belief or hope that the results of an effort will be positive, beneficial and as desired. Being optimistic means expecting the best outcome in certain situations. Optimism is one of the important determinants of various economic phenomena that has been attested by many researchers such as Lumpkin et al. (2011), Puri and Robinson (2007), and Rocciolo et al. (2019).

Even though the role of optimism in financial decision making cannot be denied, but to what extent the level of optimism can produce positive financial outcome also leads to mixed discussion. Puri and Robinson (2007), for example, found that those with moderate optimism produced more positive financial outcome than those with extreme optimism. That over-optimism at some extend can produce an unfavourable outcome for financial decisions has also been proven by other researchers such as Abildgren et al. (2018), Gugler et al. (2012), Heaton (2013).

Strömbäck et al. $(2017,2020)$ confirm that optimism also influences financial behaviour and perceived financial well-being at a personal level. Their findings confirm that those with higher optimism exhibit better financial behaviour, are not overly anxious about various financial problems and uncertainties, and are more confident about their financial security in the future. The same findings were also attested by other researchers such as Angelini and Cavapozzi (2017) and Hyytinen and Putkuri (2018). In general, they substantiate that optimism level is a relevant predictor of financial decisions and behaviour. Therefore, the hypothesis relating to optimism is formulated as follows.

H3a: Optimism has a positive effect on financial behaviour

H3b: Optimism has a positive effect on the perceived financial security

H3c: Optimism has a negative effect on the perceived financial anxiety

\section{Deliberative Thinking, Financial Behaviour and Financial Wellbeing}

One of the psychological issues regarding cognitive capabilities is deliberative and intuitive thinking. Deliberative thinking is a cognitive process in which a cautious, explicit, thoughtful and deliberate decision-making process occurs. Whereas intuitive thinking is a cognitive process which is more likely to rely on intuition that is often influenced by emotional factors. These two styles of thinking not only to affect decision making at the organisational level but also to affect decision making at the personal level (Moxley et al., 2012; Pachur \& Spaar, 2015).

According to Borghans et al. (2012), there is ample evidence in economic and psychological studies regarding the role of cognitive style as the antecedent of both economical and social outcomes. This is because cognitive style can help someone process the information before making a decision. Therefore, many economists examine the relationship of cognitive factors such as deliberative thinking both on financial decision making and financial outcomes (Moxley et al., 2012; Pachur \& Spaar, 2015; Strömbäck et al., 2017, 2020).

By including deliberative thinking as a predictor in their research, Strömbäck et al. (2017) found a positive relationship between deliberative thinking with financial behaviour and perceived financial security. That is, those who tend to think deliberately will exhibit more positive financial behaviour and have a higher sense of financial security compared to those whose tendency to think undeliberately. Therefore, the hypotheses related to deliberative thinking are formulated as follows. 
H4a: The more deliberative one thinks, the better the financial behaviour $\mathrm{H} 4 \mathrm{~b}$ : The more deliberative one thinks, the higher the perceived financial security $\mathrm{H} 4 \mathrm{c}$ : The more deliberative one thinks, the lower the perceived financial anxiety

\section{The Link of Financial Behaviour and Financial Wellbeing}

Many studies link directly some important concepts in finance such as financial literacy on financial behaviour and financial well-being (Durodola et al., 2017; Gathergood, 2012; Kamakia et al., 2017; Taft et al., 2013), but Strömbäck et al. (2017) suggest that study to investigate whether financial behaviour mediating the relationship between financial literacy and financial well-being needs to be conducted. Theoretically, financial literacy should ideally relate to financial behaviour, and financial behaviour should be related to financial wellness (Gerrans et al., 2014). Brüggen et al. (2017) also point out that financial behaviour is an important antecedent of financial well-being. Therefore, people's perception of their current and future financial security and their financial anxiety should be determined by their financial behaviour. Therefore, the next hypothesis in this study is formulated as follows:

H5a: The more favourable the financial behaviour, the higher the perceived financial security $\mathrm{H} 5 \mathrm{~b}$ : The more favourable the financial behaviour, the lower the perceived financial anxiety

\section{Research Methods}

This study is based on the survey and the data is collected using questionnaires concurrently distributed both online and offline. The sample is purposively determined following the criteria; 1) respondents' job is in the MSMEs regardless the position is the owners, managers, or employees; and 2) respondents have at least one-year engaging in MSMEs. In total, 176 questionnaires were distributed, 69 were distributed online and 107 were distributed offline. Of the total number distributed, 155 respondents were meet the criteria and were determined as the final sample to proceed to the analysis (sample descriptions can be seen in Table 1).

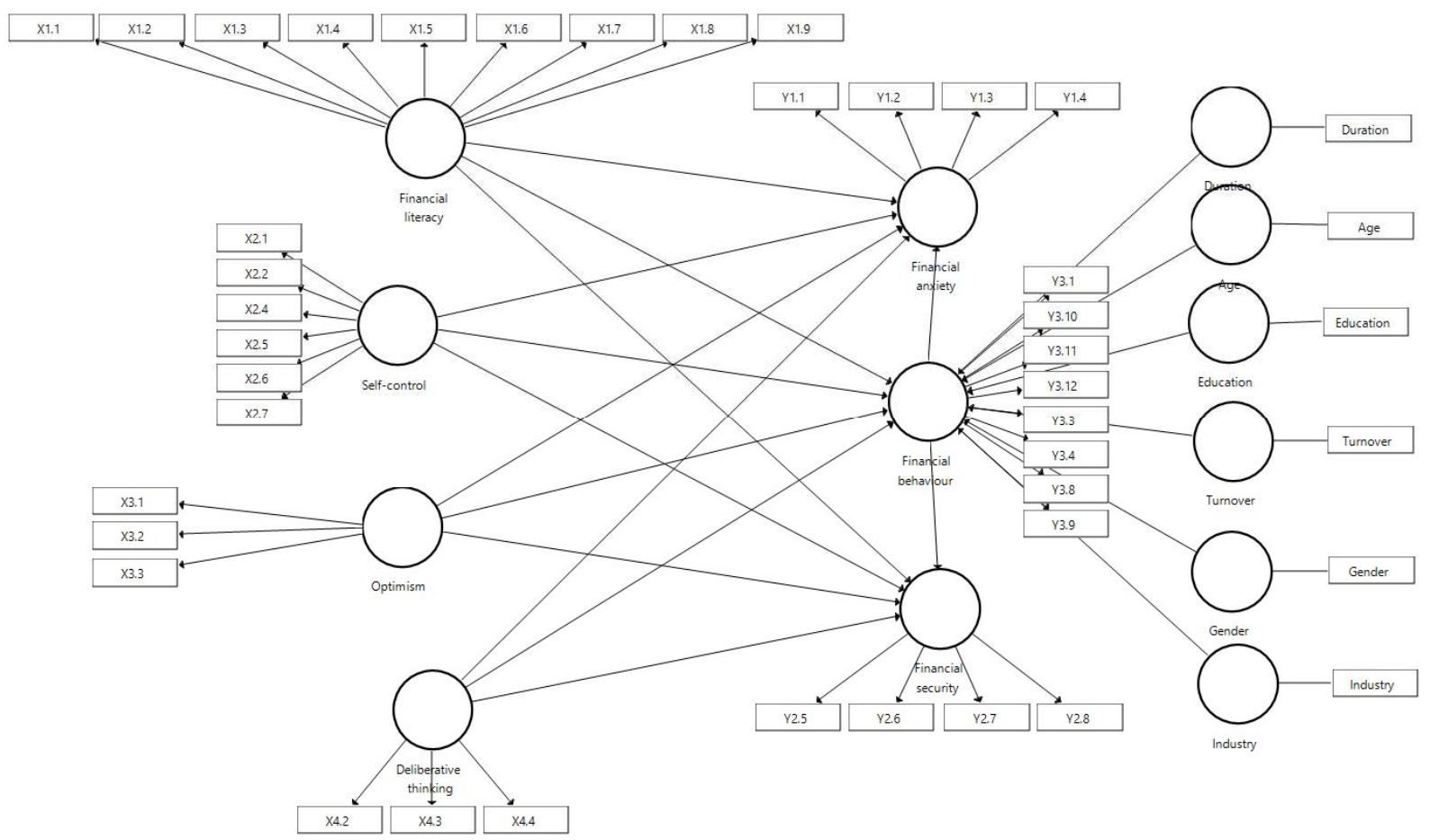

Figure 1. Research Model 
The research model is illustrated in Figure 1, and the measurements for each variable were measured using the indicators listed in Table 2. Data were then analyzed using Partial Least SquareStructural Equation Modelling (PLS-SEM). The structural equation model is based on the reflective measurements for all variables.

The validity and reliability of the measurements in Table 2 are evaluated using standard procedures in the reflective-based model, namely composite reliability, indicator reliability, convergent validity and discriminant validity. While the evaluation of the structural model is evaluated using the collinearity of the constructs, coefficient of determination $\left(\mathrm{R}^{2}\right)$, effect size $\left(f^{2}\right)$, and the significance of the path coefficient.

\section{Results and Discussion}

Table 1 presents the demographic profile of respondents in this study. The majority of respondents are women $(69.7 \%)$ and under 18 years old $(56.8 \%)$. In terms of educational background, most respondents have educational backgrounds that are not higher than junior high schools $(63.2 \%)$. While in terms of their involvement in the MSMEs business, the majority has been in the MSMEs for $1-3$ years $(72.3 \%)$. The positions of the majority of respondents are employees (44.5\%), followed by owners (27.7\%). Meanwhile, the characteristics of MSMEs are concentrated in the clothing industries $(51.6 \%)$ and have a monthly sales turnover of fewer than 5 million Rupiahs. From this overview, it appears that the majority of respondents are those who work in micro-businesses with the highest educational background are junior high schools.

Table 1. Descriptive Statistics of Respondents

\begin{tabular}{|c|c|c|c|c|c|c|c|}
\hline & Variables & Freq. & $\%$ & Median & SD & Skewness & Kurtosis \\
\hline Gender $(\mathrm{N}=155)$ & $\begin{array}{l}\text { Male } \\
\text { Female }\end{array}$ & $\begin{array}{l}47 \\
108\end{array}$ & $\begin{array}{l}30.3 \\
69.7\end{array}$ & 2.00 & 0.46 & -0.86 & -1.27 \\
\hline Age $(\mathrm{N}=155)$ & $\begin{array}{l}<18 \text { years } \\
18-28 \text { years } \\
29-39 \text { years } \\
40-50 \text { years }\end{array}$ & $\begin{array}{l}88 \\
46 \\
12 \\
9\end{array}$ & $\begin{array}{l}56.8 \\
29.7 \\
7.7 \\
5.8\end{array}$ & 1.00 & 0.86 & 1.36 & 1.15 \\
\hline $\begin{array}{l}\text { Educational } \\
\text { Background (N } \\
=155 \text { ) }\end{array}$ & $\begin{array}{l}\text { Up to Junior High School } \\
\text { Senior High School } \\
\text { Diploma } \\
\text { Bachelor Degree } \\
\text { Master Degree }\end{array}$ & $\begin{array}{l}98 \\
11 \\
39 \\
5 \\
2\end{array}$ & $\begin{array}{l}63.2 \\
7.1 \\
25.2 \\
3.2 \\
1.3\end{array}$ & 1.00 & 1.03 & 1.05 & -0.07 \\
\hline $\begin{array}{l}\text { Duration of Being } \\
\text { Engaged in SME } \\
(\mathrm{N}=155)\end{array}$ & $\begin{array}{l}1<3 \text { years } \\
3-5 \text { years } \\
>5 \text { years }\end{array}$ & $\begin{array}{l}112 \\
41 \\
2\end{array}$ & $\begin{array}{l}72.3 \\
26.5 \\
1.3\end{array}$ & 1.00 & 0.48 & 1.28 & 0.45 \\
\hline Industry $(\mathrm{N}=155)$ & $\begin{array}{l}\text { Food and Beverages } \\
\text { Clothes } \\
\text { Handicraft } \\
\text { Others }\end{array}$ & $\begin{array}{l}36 \\
80 \\
9 \\
30\end{array}$ & $\begin{array}{l}23.2 \\
51.6 \\
5.8 \\
0.2\end{array}$ & 2.00 & 1.03 & 0.75 & -0.43 \\
\hline Position $(\mathrm{N}=155)$ & $\begin{array}{l}\text { Owner } \\
\text { Manager } \\
\text { Owner and manager } \\
\text { Employee }\end{array}$ & $\begin{array}{l}43 \\
9 \\
34 \\
69\end{array}$ & $\begin{array}{l}27.7 \\
5.8 \\
21.9 \\
44.5\end{array}$ & 3.00 & 1.26 & -0.52 & -1.42 \\
\hline $\begin{array}{l}\text { Monthly Sales } \\
\text { Turnover (N } \\
=155)\end{array}$ & $\begin{array}{l}<\text { IDR } 5 \text { million } \\
\text { IDR } 5 \text { - } 10 \text { million } \\
\text { IDR } 10.1 \text { - } 15 \text { million } \\
\text { IDR } 15.1 \text { - } 20 \text { million }\end{array}$ & $\begin{array}{l}53 \\
43 \\
19 \\
40\end{array}$ & $\begin{array}{l}34.2 \\
27.7 \\
12.3 \\
25.8\end{array}$ & 2.00 & 1.19 & 0.34 & -1.41 \\
\hline
\end{tabular}


Financial behaviour and financial wellbeing of MSMEs actors:

The role of financial literacy and cognitive factors

Table 2. The results of validity and reliability test

\begin{tabular}{|c|c|c|c|c|c|c|c|}
\hline Items & Code & Mean & SD & $\begin{array}{c}\text { Outer } \\
\text { loadings }\end{array}$ & $\begin{array}{l}\text { Indicator } \\
\text { reliability }\end{array}$ & $\begin{array}{l}\text { Composite } \\
\text { reliability }\end{array}$ & AVE \\
\hline Financial literacy & & & & & & 0.914 & 0.542 \\
\hline I have a good knowledge of insurance & $X 1.1$ & 2.987 & 0.872 & 0.681 & 0.463 & & \\
\hline I have a good knowledge of saving & $\mathrm{X} 1.2$ & 3.484 & 0.675 & 0.703 & 0.494 & & \\
\hline I have a good knowledge of financial products & $\mathrm{X} 1.3$ & 3.208 & 0.762 & 0.822 & 0.675 & & \\
\hline I have a good knowledge of taxes & $\mathrm{X} 1.4$ & 3.174 & 0.866 & 0.644 & 0.415 & & \\
\hline I well know regulation related to customer protections & $\mathrm{X} 1.5$ & 3.252 & 0.816 & 0.651 & 0.424 & & \\
\hline I have a good knowledge of how to prepare my pension & $X 1.6$ & 3.226 & 0.816 & 0.812 & 0.660 & & \\
\hline I have a good knowledge of investment & $\mathrm{X} 1.7$ & 3.316 & 0.809 & 0.798 & 0.637 & & \\
\hline I have a good knowledge of bonds and stocks & $\mathrm{X} 1.8$ & 2.955 & 0.904 & 0.734 & 0.539 & & \\
\hline $\begin{array}{l}\text { In general, I well understand money market and } \\
\text { economic conditions }\end{array}$ & X1.9 & 3.252 & 0.927 & 0.755 & 0.571 & & \\
\hline Self-control & & & & & & 0.863 & 0.513 \\
\hline I find it hard to change bad habits & $\mathrm{X} 2.1$ & 3.374 & 1.125 & 0.723 & 0.522 & & \\
\hline I am easily distracted (hard to focus) & $\mathrm{X} 2.2$ & 3.394 & 1.133 & 0.762 & 0.580 & & \\
\hline I often do fun things now, then regret it & $\mathrm{X} 2.4$ & 3.394 & 1.038 & 0.668 & 0.446 & & \\
\hline I often act without thinking of alternatives & $\mathrm{X} 2.5$ & 3.548 & 0.945 & 0.720 & 0.519 & & \\
\hline I only focus on short-term goals & $\mathrm{X} 2.6$ & 3.594 & 0.878 & 0.729 & 0.531 & & \\
\hline I think the future will take care of itself & $\mathrm{X} 2.7$ & 3.768 & 1.021 & 0.691 & 0.477 & & \\
\hline Optimism & & & & & & 0.772 & 0.543 \\
\hline In an uncertainty condition, I always expect the best & X3.1 & 3.845 & 0.931 & 0.808 & 0.653 & & \\
\hline $\begin{array}{l}\text { In my opinion, something wrong or bad can always } \\
\text { happen }\end{array}$ & $\mathrm{X} 3.2$ & 3.723 & 0.934 & 0.488 & 0.238 & & \\
\hline I am always optimistic about my future & X3.3 & 4.161 & 0.854 & 0.859 & 0.738 & & \\
\hline Deliberative thinking & & & & & & 0.827 & 0.616 \\
\hline I like to analyze various problems & $\mathrm{X} 4.2$ & 3.594 & 0.817 & 0.739 & 0.547 & & \\
\hline When making a decision, I do it in deliberative stages & $\mathrm{X} 4.3$ & 3.787 & 0.736 & 0.802 & 0.644 & & \\
\hline $\begin{array}{l}\text { Before making a decision, I always think about the } \\
\text { goals to be achieved }\end{array}$ & $\mathrm{X} 4.4$ & 4.09 & 0.676 & 0.810 & 0.656 & & \\
\hline Financial anxiety & & & & & & 0.863 & 0.613 \\
\hline I do not understand the terms in finance & Y1.1 & 2.935 & 0.751 & 0.700 & 0.491 & & \\
\hline I am anxious about my money and financial matters & $\mathrm{Y} 1.2$ & 2.852 & 0.893 & 0.830 & 0.690 & & \\
\hline I tend to postpone financial decisions & Y1.3 & 2.632 & 0.835 & 0.815 & 0.664 & & \\
\hline $\begin{array}{l}\text { I am worried whether the financial decision I } \\
\text { made is right or wrong }\end{array}$ & Y1.4 & 2.91 & 0.845 & 0.780 & 0.608 & & \\
\hline Financial security & & & & & & 0.823 & 0.541 \\
\hline I feel safe with my current financial condition & Y2.5 & 3.323 & 0.826 & 0.671 & 0.450 & & \\
\hline I am confident in my financial condition in the future & Y2.6 & 3.645 & 0.921 & 0.835 & 0.697 & & \\
\hline $\begin{array}{l}\text { I am sure that I have enough money to support } \\
\text { myself after retirement }\end{array}$ & Y2.7 & 3.471 & 0.999 & 0.779 & 0.607 & & \\
\hline Caring about the financial future is important to me & Y2.8 & 4.026 & 1.025 & 0.640 & 0.410 & & \\
\hline Financial behaviour & & & & & & 0.839 & 0.497 \\
\hline Carrying out the activities in the last 6 months; & & & & & & & \\
\hline $\begin{array}{l}\text { Comparing prices when shopping } \\
\text { Recording expenses every month }\end{array}$ & $\begin{array}{l}\text { Y3.1 } \\
\text { Y3.3 }\end{array}$ & $\begin{array}{l}3.697 \\
3.071\end{array}$ & $\begin{array}{l}1.031 \\
1.197\end{array}$ & $\begin{array}{l}0.561 \\
0.636\end{array}$ & $\begin{array}{l}0.315 \\
0.404\end{array}$ & & \\
\hline Shopping according to the planned budget & Y3.4 & 3.561 & 1.108 & 0.632 & 0.399 & & \\
\hline Starting or maintaining an emergency fund & Y3.8 & 3.652 & 1.013 & 0.699 & 0.489 & & \\
\hline Always saving once receiving a salary (income) & Y3.9 & 4.058 & 0.945 & 0.682 & 0.465 & & \\
\hline $\begin{array}{l}\text { Savings for long-term goals (education, home, } \\
\text { vehicle, etc.) }\end{array}$ & Y3.10 & 4.013 & 1.003 & 0.729 & 0.531 & & \\
\hline Setting aside money for pension funds & Y3.11 & 3.484 & 1.193 & 0.563 & 0.316 & & \\
\hline Investing by buying stocks, bonds or mutual funds & Y3.12 & 2.219 & 1.326 & 0.507 & 0.257 & & \\
\hline
\end{tabular}

Note: Items for variables are adopted from Strömbäck et al. (2017b). The likert-based scale is used for measurement, ranging from 1 (strongly disagree) to 5 (strongly agree) for all items except for a set of items for financial behaviour $(1=$ never, $5=$ always)

When data tabulation is carried out and the evaluation of measurements is conducted, there are some initial indicators on some variables that are excluded from the set of indicators because the indicators do not meet the reliability. Three indicators $(\mathrm{X} 2.3, \mathrm{X} 2.8, \mathrm{X} 2.9)$ are excluded from the self- 
control variable, two indicators $(\mathrm{X} 3.4, \mathrm{X} 3.5)$ are excluded from the optimism variable, one indicator (X4.1) is excluded from the deliberative thinking variable, and four other indicators (Y3.2, Y.3.5, Y3.6, Y3.7) are excluded from financial behaviour variable. These indicators are removed because the outer loadings are smaller than 0.40 . There are also indicators whose outer loadings are $>0.40-0.60$ but are excluded from the set of indicators because its removal scenario can significantly increase composite reliability. Table 2 contains the final set of indicators included in the analysis and the results of validity and reliability test.

In general, some final indicators are still below the threshold of indicator reliability. This can be seen from the outer loadings which still tend to be low $(<0.708)$ and the reliability indicator that are $<0.50$. However, these indicators remain because, in addition to reasons for content validity, the internal reliability of the variable is quite high (0.70). Hair Jr. et al. (2014) argue that in the social sciences, indicators with the outer loadings of $0.40-0.70$ should not be directly excluded from the set of indicators and suggest to maintain the indicators as long as the content is relevant and the composite reliability is high. Besides, the convergent validity is also meet for all variables (AVE> 0.50 ), except for financial behaviour variables whose AVE $<0.50$. However, because our evaluations of its content and discriminant validity are met, the elimination of such indicators to increase AVE was not carried out. Also, the AVE is only slightly lower than the minimum threshold (0.497), so that discriminant validity is considered acceptable.

Table 3 presents the results of the discriminant validity for all variables. In general, the FornellLarcker (in bold) in each construct is higher than the correlation of the corresponding construct with other constructs in the model. This means that each construct is unique and can capture phenomena that are not represented by other constructs. Therefore, based on the evaluation results of the measurements, further analysis of the structural model can be carried out.

Meanwhile, the results of structural model evaluation confirm that there is no collinearity for all constructs which means that all constructs are relevant to be available in the model. $\mathrm{R}^{2}$ for financial behaviour, financial security and financial anxiety are $0.227,0.290$, and 0.327 , respectively. Although such explanatory power is quite weak, $\mathrm{R}^{2}$ is still higher than 0.20 which is considered acceptable in a certain discipline (Hair Jr. et al., 2014) such as personal finance. While $f^{2}$ exhibit varied effect of financial literacy, self-control, optimism, and deliberative thinking on financial behaviour, financial security and financial anxiety. The effect size ranges from small to medium whereby self-control has the largest contribution to financial anxiety $\left(f^{2}=0.192\right)$. Because in SEM there is no specific rule of thumb for the fitness of structural model that is widely accepted, direct evaluation to the path coefficient is conducted.

The results of the hypotheses testing on the structural model are presented in Table 4. The tests were carried out using the bootstrapping procedure with 5000 sub-sample scenarios. From Table 4 , it can be seen that not all hypotheses in the structural path are confirmed. Financial literacy is confirmed to have a positive relationship both on financial behaviour (0.077) and financial security (0.296), but the effect is only significant in financial security $(\mathrm{P}$-value $=0.002)$. Meanwhile, although confirmed negative (-0.171), the effect of financial literacy on financial anxiety is not significant (Pvalue $=0.344$ ). That is, the high financial literacy of MSMEs actors is significantly correlated only to financial security, which means that the higher the level of financial literacy, the higher the perception of financial security of MSMEs' actors. However, the high level of financial literacy is not significantly able to explain the variations of financial behaviour and financial anxiety.

This finding is similar with and at the same time are also different from the results of Strömbäck et al. (2017b, 2020). Strömbäck et al. (2017b) prove the positive influence of financial literacy on financial behaviour and the perceived financial security and also prove the negative influence of financial literacy on perceived financial anxiety. But when another testing was conducted on students using experiments, Strömbäck et al. (2020) did not find any effect of financial literacy on the variables. The findings of our study are also in line with the findings of Taft et al. (2013) which confirms the positive influence of financial literacy on financial well-being. 


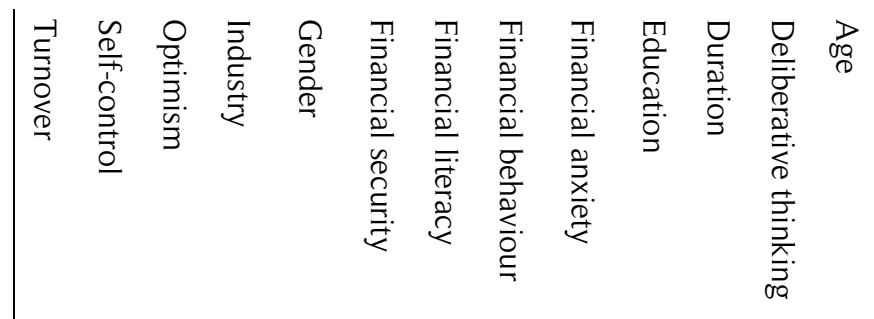

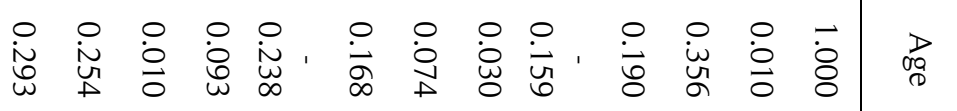

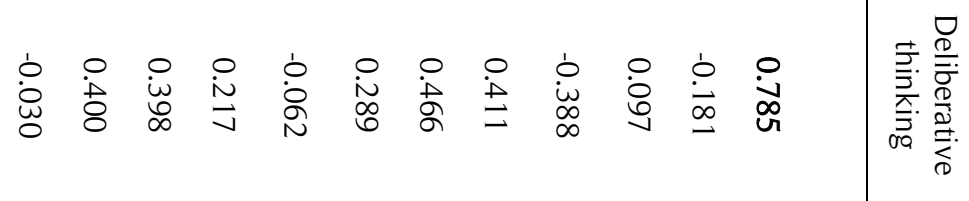

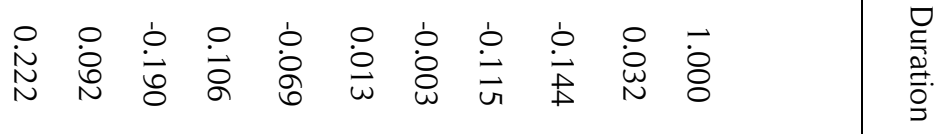

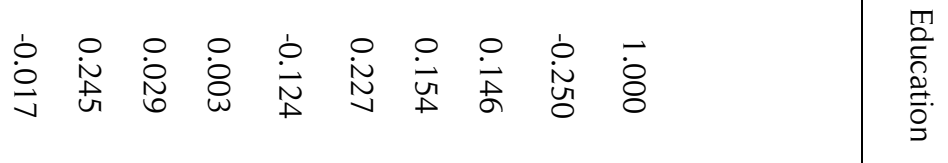

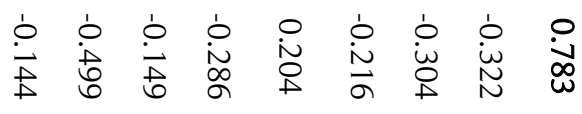

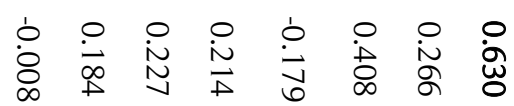

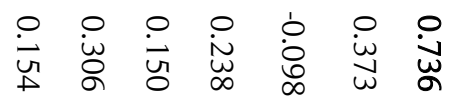

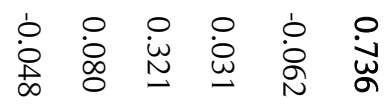

$$
\begin{aligned}
& \begin{array}{lllll}
\dot{0} & \dot{0} & \dot{0} & 0 & \dot{0} \\
\dot{\vec{t}} & \dot{0} & \stackrel{0}{0} & \stackrel{0}{0} & \dot{8}
\end{array}
\end{aligned}
$$

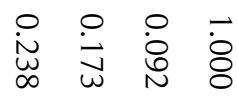

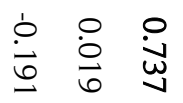

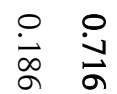

$$
\begin{aligned}
& \dot{8}
\end{aligned}
$$


Table 4. The result of the hypothesis test

\begin{tabular}{lrrrrr}
\hline & $\begin{array}{l}\text { Original } \\
\text { Sample (O) }\end{array}$ & $\begin{array}{l}\text { Sample } \\
\text { Mean } \\
\text { (M) }\end{array}$ & $\begin{array}{l}\text { Standard } \\
\text { Deviation } \\
\text { (STDEV) }\end{array}$ & $\begin{array}{l}\text { T Statistics } \\
\text { (IO/STDEVI) }\end{array}$ & P Values \\
\hline Age -> Financial behaviour & -0.012 & -0.01 & 0.113 & 0.101 & 0.919 \\
Deliberative thinking -> Financial anxiety & -0.098 & -0.104 & 0.091 & 1.071 & 0.284 \\
Deliberative thinking -> Financial behaviour & 0.295 & 0.291 & 0.101 & 2.927 & $0.003^{* * *}$ \\
Deliberative thinking -> Financial security & -0.041 & -0.043 & 0.11 & 0.375 & 0.708 \\
Duration -> Financial behaviour & -0.068 & -0.065 & 0.078 & 0.874 & 0.382 \\
Education -> Financial behaviour & 0.089 & 0.086 & 0.081 & 1.097 & 0.273 \\
Financial behaviour -> Financial anxiety & -0.175 & -0.171 & 0.075 & 2.313 & $0.021^{* *}$ \\
Financial behaviour -> Financial security & 0.306 & 0.311 & 0.092 & 3.304 & $0.001^{* * *}$ \\
Financial literacy_-> Financial anxiety & -0.081 & -0.082 & 0.086 & 0.945 & 0.344 \\
Financial literacy_-> Financial behaviour & 0.062 & 0.077 & 0.093 & 0.662 & 0.508 \\
Financial literacy_-> Financial security & 0.294 & 0.296 & 0.097 & 3.031 & $0.002^{* * *}$ \\
Gender -> Financial behaviour & -0.142 & -0.144 & 0.084 & 1.689 & $0.091^{*}$ \\
Industry -> Financial behaviour & 0.132 & 0.122 & 0.079 & 1.668 & $0.095^{*}$ \\
Optimism -> Financial anxiety & -0.051 & -0.052 & 0.08 & 0.635 & 0.525 \\
Optimism -> Financial behaviour & 0.056 & 0.063 & 0.102 & 0.553 & 0.580 \\
Optimism -> Financial security & 0.225 & 0.229 & 0.106 & 2.125 & $0.034^{* *}$ \\
Self-control_-> Financial anxiety & -0.402 & -0.407 & 0.076 & 5.318 & $0.000^{* * *}$ \\
Self-control_-> Financial behaviour & 0.015 & 0.025 & 0.103 & 0.141 & 0.888 \\
Self-control_-> Financial security & -0.054 & -0.053 & 0.087 & 0.623 & 0.533 \\
Turnover -> Financial behaviour & -0.032 & -0.032 & 0.098 & 0.33 & 0.742 \\
\hline
\end{tabular}

Note: $*, * *$, and $* * *$ denotes coefficient significance at alpha 10,5 , and $1 \%$, respectively

Self-control is found to have a negative effect (-0.402) on financial anxiety (P-value $=0.000)$, which means that the higher the self-control of MSMEs' actors, the perceived financial anxiety will decrease. However, the effect of self-control on financial behaviour and financial security is not significant (P-value $=0.888$ and 0.533 , respectively). This indicates that high self-control is not able to explain the variability of financial behaviour, but can explain the variability of financial well-being partially through a decrease in financial anxiety. The findings of our study are also slightly different from those found by Strömbäck et al. (2017b, 2020), which confirms the positive influence of selfcontrol on financial behaviour and perceived financial security and the negative effect of self-control on perceived financial anxiety. In our study, the test result only proves the negative effect of selfcontrol on financial anxiety.

In literature, it is stated that the higher the level of self-control, the financial decision and the outcome will also be better (Gathergood, 2012; Liu et al., 2019). This is consistent with the behavioural life cycle theory which states that a person's financial behaviour throughout his/her life cycle will be largely determined by his/her ability to control impulse (Shefrin \& Thaler, 1988). The findings of this study cannot directly confirm the behavioural life cycle theory concerning financial behaviour but have succeeded in confirming that self-control has a negative direct effect on financial anxiety. The insignificance of the effect of self-control on financial behaviour can be caused by the distribution of respondents in this study which is concentrated on those who are young ( $<18$ years). Thus, their high cognitive dissonance may lead their self-control is not fully manifested into their financial behaviour.

Meanwhile, the test results on the effect of optimism confirm the positive influence of optimism $(0.225)$ on perceived financial security $(P$-value $=0.034)$. This effect is not confirmed on 
financial behaviour and financial anxiety, although the sign of the coefficient is consistent with the hypothesised. That is, the higher an individual optimism, the subjective perception of financial security will also be higher. This result also has the compatibility and at the same time incompatible with the results of the study by Strömbäck et al. (2017b, 2020). Strömbäck et al. (2017b) confirm the influence of optimism on all variables, which is positive on financial behaviour and financial security and negative on financial anxiety. However, in another study, Strömbäck et al. (2020) failed to maintain evidence of the positive influence of optimism on financial behaviour. In the literature, the effect of optimism itself on financial behaviour and outcomes is not always positive. In some cases, overoptimism worsens the financial decisions and the outcomes (Hyytinen \& Putkuri, 2018; Puri \& Robinson, 2007).

Other test results on the effect of deliberative thinking confirm the positive influence of deliberative thinking (0.295) on financial behaviour (P-value $=0.003)$. While the effect of deliberative thinking on financial security and financial anxiety is not significant. That is, the more deliberative the way one thinks, the better his financial behaviour. This result is somewhat interesting because, among the three other cognitive factors, only deliberative thinking that has a positive effect on financial behaviour. This means that careful, deliberative, and systematic thought contribute significantly more in shaping good financial behaviour than the level of optimism and self-control. Slightly different from the research of Strömbäck et al. (2017b) which confirms the positive influence of deliberative thinking on financial behaviour and financial security, the results of our test only confirm the positive influence of deliberative thinking on financial behaviour. This is consistent with the results of another study by Strömbäck et al. (2020) which only confirm the positive influence of deliberative thinking on financial behaviour, but not on perceived financial security and anxiety. This also corroborates with the findings of Moxley et al. (2012) which found that deliberative thinking can provide greater benefits for decision-makers, no matter the decisions are difficult or easy to take.

We also include control variables in the structural model (Figure 1) with the initial assumption that the demographic characteristics of respondents consisting of age, gender, educational background, and duration of involvement in MSMEs as well as MSMEs' characteristics such as industry type and sales turnover will contribute to financial behaviour. Simultaneous test results only confirm the effect of gender and industry. In brief, this means that there are differences in the variability of financial behaviour in terms of the gender and type of industry. These findings can be anticipated by the next works.

In addition to directly linking financial literacy, self-control, optimism and deliberative thinking on financial behaviour, financial security and financial anxiety, this study also functions the financial behaviour as a mediating variable on the effect of financial literacy, self-control, optimism, and deliberative thinking on financial security and financial anxiety. However, because the direct influence of such variables on financial behaviour is generally not significant, except for deliberative thinking, the mediating effect of financial behaviour on financial security and financial anxiety is not confirmed, except for the path derived from deliberative thinking. The financial behaviour has a direct positive effect $(0.306)$ on financial security $(P$-value $=0.001)$ and has a direct negative effect $(-0.175)$ on financial anxiety (P-value $=0.021)$. This amplifies that the better the financial behaviour, the higher the perceived financial security towards current and future financial conditions, and the lower the perceived financial anxiety of financial uncertainties. The positive influence of financial behaviour on financial wellbeing which in this study is proxied by financial security and financial anxiety is following the findings of several researchers such as Gerrans et al. (2014), Chu et al. (2017), and Strömbäck et al. (2020) who found a positive relationship of financial behaviour with the quality of financial outcomes.

\section{Conclusion and Future Direction}

The findings of this study confirm that the financial well-being of MSMEs that are proxied by financial security and financial anxiety are positively influenced by financial behaviour. Meanwhile, financial 
behaviour cannot be explained by financial literacy, optimism, and self-control, and can only be explained by deliberative thinking which means that the more deliberative the one thinks, the more favourable his/her financial behaviour. Financial security can be explained positively by financial literacy and optimism which means that the more financially literated and the more optimistic the individuals, the higher their perceived security towards their financial conditions in the present and the future. Meanwhile, financial anxiety is negatively affected by self-control which means that the better the one's self-control, the lower the anxiety of financial uncertainty.

The results of this study provide important implications for policymakers regarding the efforts to improve the financial wellbeing of MSMEs' actors who are important supporters of the Indonesian economy. Based on these results, further efforts are needed to find a relevant series of important determinants of the financial behaviour of MSMEs' actors. The unrelated financial behaviour of MSME actors with the level of financial literacy, optimism and self-control implies the complexity of MSME actors' behaviour which may need to be approached with more complex behavioural modelling. It is widely known that the main source of funding of the majority of MSMEs generally comes from the owners and their people management is not entirely based on performance as in large companies. Therefore, the financial behaviour of MSMEs' actors may be more complexly determined by a series of other behavioural factors. In addition to anticipating the intended modelling, the next researcher can also expand the scope of the sample and the scope of MSMEs so that the generalizability of the results can be concluded more robustly. The design of a multi-group analysis is also worth considering so that the mapping of the relevant determinants of the financial wellbeing for MSMEs' actors can be more comprehensively portrayed.

\section{References}

Abildgren, K., Hansen, N. L., \& Kuchler, A. (2018). Overoptimism and house price bubbles. Journal of Macroeconomics, 56(June 2017), 1-14.

Agarwal, S., \& Mazumder, B. (2013). Cognitive abilities and household financial decision making. American Economic Journal: Applied Economics, 5(1), 193-207.

Ameriks, J., Caplin, A., Leahy, J., \& Tyler, T. (2007). Measuring Self-Control Problems. The American Economic Review, 97(3), 966-972.

Angelini, V., \& Cavapozzi, D. (2017). Dispositional optimism and stock investments. Journal of Economic Psychology, 59, 113-128.

Asiedu, E., \& Freeman, J. A. (2007). The effect of globalization on the performance of small- And medium-sized enterprises in the United States: Does owners' race/ethnicity matter? American Economic Review, 97(2), 368-372.

Nimalathasan, B. (2008). A Relationship Between Owner-Manager' Characteristics and Business Performance. LESIJ - Lex ET Scientia International Journal, 15(1), 61-68.

Blackburn, R. A., Hart, M., \& Wainwright, T. (2013). Small business performance: business, strategy and owner-manager characteristics. Journal of Small Business and Enterprise Development, 20(1), 8-27.

Bloch, H., \& Bhattacharya, M. (2016). Promotion of Innovation and Job Growth in Small- and Medium-Sized Enterprises in Australia: Evidence and Policy Issues. Australian Economic Review, 49(2), 192-199.

Brüggen, E. C., Hogreve, J., Holmlund, M., Kabadayi, S., \& Löfgren, M. (2017). Financial well-being: A conceptualization and research agenda. Journal of Business Research, 79, 228-237.

Buyinza, F., Mutenyo, J., Kakande, N., \& Banga, M. (2017). Determinats of firm start-up size and 
performance of small and medium enterprises (SMEs): Empirical evidence from Uganda. Journal of Applied Business and Economics, 19(12), 2017.

Chu, Z., Wang, Z., Xiao, J. J., \& Zhang, W. (2017). Financial Literacy, Portfolio Choice and Financial Well-Being. Social Indicators Research, 132(2), 799-820.

Cronqvist, H., Makhija, A. K., \& Yonker, S. E. (2012). Behavioral consistency in corporate finance: CEO personal and corporate leverage. Journal of Financial Economics, 103(1), 20-40.

Durodola, O., Fusch, P., \& Tippins, S. (2017). A Case-Study of Financial Literacy and Wellbeing of Immigrants in Lloydminster, Canada. International Journal of Business and Management, 12(8), 37.

Gathergood, J. (2012). Self-control, financial literacy and consumer over-indebtedness. Journal of Economic Psychology, 33(3), 590-602.

Gerrans, P., Speelman, C., \& Campitelli, G. (2014). The Relationship Between Personal Financial Wellness and Financial Wellbeing: A Structural Equation Modelling Approach. Journal of Family and Economic Issues, 35(2), 145-160.

Graham, F., \& Isaac, A. G. (2002). The behavioral life-cycle theory of consumer behavior: Survey evidence. Journal of Economic Behavior and Organization, 48(4), 391-401.

Gugler, K., Mueller, D. C., Weichselbaumer, M., \& Yurtoglu, B. (2012). Market Optimism and Merger Waves. Managerial and Decision Economics, 33(2), 149-163.

Hair Jr., J. F., Hult, G. T. M., RIngle, C. M., \& Sarstedt, M. (2014). A Primer on Partial Least Squares Structural Equation Modeling (PLS-SEM). Sage Publication Asia-Pacific.

Hastings, J. S., Madrian, B. C., \& Skimmyhorn, W. L. (2013). Financial Literacy , Financial Education , and Economic Outcomes. Annual Review of Economics, 5(1), 347-376.

Heaton, J. B. (2013). Managerial Optimism and Corporate finance. Financial Management, 31(2), 3345.

Hyytinen, A., \& Putkuri, H. (2018). Household Optimism and Overborrowing. Journal of Money, Credit and Banking, 50(1), 55-76.

Kamakia, M. G., Mwangi, C. I., \& Mwangi, M. (2017). Financial Literacy and Financial Wellbeing of Public Sector Employees: A Critical Literature Review. European Scientific Journal, ESJ, 13(16), 233.

Levin, L. (1998). Are assets fungible?: Testing the behavioral theory of life-cycle savings. Journal of Economic Behavior and Organization, 36(1), 59-83.

Liu, F., Yilmazer, T., Loibl, C., \& Montalto, C. (2019). Professional financial advice, self-control and saving behavior. International Journal of Consumer Studies, 43(1), 23-34.

Lumpkin, G. T., Steier, L., \& Wright, M. (2011). Financial Optimism and Entrepreneurial Satisfaction. Strategic Entrepreneurship Journal, 306, 285-306.

Maliranta, M., \& Nurmi, S. (2019). Business owners, employees, and firm performance. Small Business Economics, 52(1), 111-129.

Moxley, J. H., Anders Ericsson, K., Charness, N., \& Krampe, R. T. (2012). The role of intuition and deliberative thinking in experts' superior tactical decision-making. Cognition, 124(1), 72-78.

Murphy, G., Tocher, N., \& Burch, T. (2019). Small business owner persistence: Do personal characteristics matter? Journal of Small Business Strategy, 29(1), 92-107. 
Myrseth, K. O. R., \& Fishbach, A. (2009). Self-Control. Current Directions in Psychological Science, 18(4), 247-252.

Ndiaye, N., Abdul Razak, L., Nagayev, R., \& Ng, A. (2018). Demystifying small and medium enterprises' (SMEs) performance in emerging and developing economies. Borsa Istanbul Review, 18(4), 269-281.

Pachur, T., \& Spaar, M. (2015). Domain-specific preferences for intuition and deliberation in decision making. Journal of Applied Research in Memory and Cognition, 4(3), 303-311.

Puri, M, \& Robinson, D. (2007). Optimism and economic choice. Journal of Financial Economics, 86(1), 71-99.

Puri, Manju, \& Robinson, D. T. (2007). Optimism and economic choice. Journal of Financial Economics, 86, 71-99.

Quartey, S. H., \& Oguntoye, O. (2020). Promoting corporate sustainability in small and medium-sized enterprises: Key determinants of intermediary performance in Africa. Business Strategy and the Environment, 29(3), 1160-1172.

Remund, D. L. (2010). Financial Literacy Explicated: The Case for a Clearer Definition in an Increasingly Complex Economy. The Journal of Consumer Affairs, 44(2), 276-295.

Rha, J. Y., Montalto, C. P., \& Hanna, S. D. (2006). The effect of self-control mechanisms on household saving behavior. Journal of Financial Counseling and Planning, 17(2), 3-16.

Rocciolo, F., Gheno, A., \& Brooks, C. (2019). Optimism, volatility and decision-making in stock markets. International Review of Financial Analysis, 66(September 2018), 101356.

Sato, Y. (2000). How did the crisis affect small and medium-sized enterprises? From a field study of the metal-working industry in Java. Developing Economies, 38(4), 572-595.

Schooley, B. D. K., \& Worden, D. D. (2008). A Behavioral Life- Cycle Approach to Understanding the Wealth Effect. Business Economics, 43(2), 7-15.

Shefrin, H. M., \& Thaler, R. H. (1988). The behavioral life-cycle hypothesis. Economic Inquiry, 26(10), 609-643.

Sherman, R. A., Nave, C. S., \& Funder, D. C. (2010). Situational similarity and personality predict behavioral consistency. Journal of Personality and Social Psychology, 99(2), 330-343.

Skagerlund, K., Lind, T., Strömbäck, C., Tinghög, G., \& Västfjäll, D. (2018). Financial literacy and the role of numeracy-How individuals' attitude and affinity with numbers influence financial literacy. Journal of Behavioral and Experimental Economics , 74(March), 18-25.

Strömbäck, C., Lind, T., Skagerlund, K., Västfjäll, D., \& Tinghög, G. (2017). Does self-control predict financial behavior and financial well-being? Journal of Behavioral and Experimental Finance, 14, 30-38.

Strömbäck, C., Skagerlund, K., Västfjäll, D., \& Tinghög, G. (2020). Subjective self-control but not objective measures of executive functions predicts financial behavior and well-being. Journal of Behavioral and Experimental Finance, 27, 100339.

Taft, M. K., Hosein, Z. Z., \& Mehrizi, S. M. T. (2013). The Relation between Financial Literacy, Financial Wellbeing and Financial Concerns. International Journal of Business and Management, 8(11), 63-75.

Tambunan, T. (2005). Promoting small and medium enterprises with a clustering approach: A policy experience from Indonesia. Journal of Small Business Management, 43(2), 138-154. 
Tambunan, T. T. H. (2019). The impact of the economic crisis on micro, small, and medium enterprises and their crisis mitigation measures in Southeast Asia with reference to Indonesia. Asia and the Pacific Policy Studies, 6(1), 19-39.

Topa, G., Hernández-Solís, M., \& Zappalà, S. (2018). Financial management behavior among young adults: The role of need for cognitive closure in a three-wave moderated mediation model. Frontiers in Psychology, 9(NOV), 1-10.

Woldesilassie, T. L., \& Ivatury, V. M. K. (2020). Key Determinant Factors Affecting the Performance of Small and Medium Scale Manufacturing Enterprise: A Case Study on West Shoa Zone, Oromia National Regional State, Ethiopia. International Journal of Engineering Research And, 09(02), 555-562.

Xiao, J. J. (2008). Handbook of Consumer Finance Research. In J. J. Xiao (Ed.), Handbook of Consumer Finance Research (Issue August). Springer New York. 